\title{
Divergence insufficiency associated with high myopia
}

This article was published in the following Dove Press journal:

Clinical Ophthalmology

21 December 2010

Number of times this article has been viewed

\section{Hiromi Kohmoto \\ Kenji Inoue \\ Masato Wakakura}

Inouye Eye Hospital, Chiyoda-ku, Tokyo, Japan
Correspondence: Hiromi Kohmoto Inouye Eye Hospital, Shin Ochanomizu Building 4-3, Kanda-Surugadai, Chiyoda-ku, Tokyo, I0I-0062 Japan Tel +8I 03 (3295) 0190

$\mathrm{Fax}+8 \mathrm{I} 03$ (3295) 0917

Email hkohmoto@nifty.com
Purpose: Divergence insufficiency is generally regarded as a neurological event. While high myopia is not a well-known cause of divergence insufficiency, we frequently encounter divergence insufficiency in high-myopia patients. Thus, the purpose of this study was to report detailed information on such cases and examine mechanisms that might potentially be responsible for this disorder.

Methods: We investigated 20 cases of high myopia ( $>-6$ D) with divergence insufficiency, 20 cases of high myopia without double vision, and 10 normal cases as controls. Using magnetic resonance imaging (MRI), a coronal image $6 \mathrm{~mm}$ anterior to the eyeball-optic nerve junction was measured and used to examine the extraocular muscle (EOM) path shift and angle of the eye. Higher angles in each patient were used for statistical comparison.

Results: In high-myopia patients with divergence insufficiency, ocular axis measurements ranged from 24.8 to 31.0 (mean \pm SD: $27.6 \pm 1.6$ ) $\mathrm{mm}$. In high-myopia patients without double vision, the ocular axis length was $27.6 \pm 1.3 \mathrm{~mm}$. In normal cases, the ocular axis length was $23.5 \pm 1.0 \mathrm{~mm}$. The EOM angles in these patients ranged from 100 to $140(112.9 \pm 9.7)$ degrees, which was significantly higher $(P<0.05)$ than that seen in the high-myopia patients without double vision (average EOM angle, $99.2 \pm 2.8$ degrees) and normal cases (average EOM angle, $97.9 \pm 3.8$ degrees $)$. However, orbital lengths in the patients were 41.0 to $48.9(44.6 \pm 2.3) \mathrm{mm}$, which also differed from the high-myopia patients without double vision (average orbital length, $49.9 \pm 2.0 \mathrm{~mm}$ ) significantly $(P<0.05)$. In normal cases, average orbital length was $45.5 \pm 1.6 \mathrm{~mm}$

Conclusion: In high-myopia patients with divergence insufficiency, nasal shift of the superior rectus and an inferior shift of the lateral rectus were observed, but the orbital lengths were normal. Divergence insufficiency may be caused mechanically by shifts of the EOM due to the presence of a long axis. Therefore, high myopia with a long axis can be considered to be a risk factor for the occurrence of divergence insufficiency.

Keywords: divergence insufficiency, high myopia, MRI, extraocular muscle

\section{Introduction}

Divergence insufficiency has often been thought to be induced by a neurological disorder of the central nervous system. Although high myopia has not been considered to be a cause of divergence insufficiency, we have frequently observed high-myopia patients with divergence insufficiency in the absence of other neurological disorders. Restrictive ocular motility disturbances associated with high myopia have been described via the use of computed tomography (CT) and magnetic resonance imaging (MRI). ${ }^{1}$ Yokoyama have reported that both the lateral rectus and superior rectus shifts were caused by an elongated posterior portion of the eyeball related to the high myopia. ${ }^{2}$ 
In the present study, we used MRI to characterize the clinical features and assess the shift of extraocular muscle (EOM) that occurs in these patients.

\section{Patients and methods}

We studied cases with divergence insufficiency and high myopia in our neuro-ophthalmology clinic. To be enrolled in the study, patients had to meet the following 5 criteria: 1) relatively sudden onset of double vision at far vision, 2) no double vision at near vision, 3 ) high myopia $>-6.0$ diopters (D) in both eyes, 4) no other neurological symptoms, and 5) a normal brain MRI study. Any subjects with abduction palsy at the initial presentation were excluded from the study. A total of 4 male and 16 female patients met the criteria. Patients ranged in age from 42 to 76 years $(58.9 \pm 8.6)$, had follow-up periods from 2 to 10 years, and did not have low vision, strabismus, or amblyopia. Next we examined 20 cases of high myopia without double vision and 10 normal cases as controls following 4 criteria: refraction $<-4.0 \mathrm{D}$, without double vision, no other neurological symptoms, and normal brain MRI.

We employed spherical equivalent transportation to calculate refraction via an auto refractometer (Nidek ARK-530A ${ }^{\circledR}$; Aichi, Japan). We measured the ocular axis 5 times in each eye using A mode echography (Carl Zeiss IOL Master $^{\circledR}$; Jena, Germany). We used an alternating prism cover test (APCT) to determine the eye position at far $(5 \mathrm{~m})$ and near $(30 \mathrm{~cm})$ vision. Orbital MRI was used to determine the extraocular muscle path shift. MRI was carried out with a 1.5 Tesla imager (Intera Achieva; Philips, Best, The Netherlands) with head coil. T 2-weighted imaging (T2WI) was obtained vertically to the optic nerve. The imaging parameters of $\mathrm{T} 2 \mathrm{WI}$ were set as follows: repetition time (TR), 2000 milliseconds (msec); echo time (TE), 85 msec; matrix, $78 \times 80$; field of view, $100 \times 100 \mathrm{~mm}$; slice thickness, $3 \mathrm{~mm}$; interval gap, $0.3 \mathrm{~mm}$; number of excitations 2 . A coronal slice image $6 \mathrm{~mm}$ anterior to the eyeball-optic nerve junction was chosen for the measurement of the EOM path shift. After tracing the outline of the cross-sectional eyeball and EOM, we then determined their centroids. Lines were drawn between the eyeball and the EOM and used to measure the angle of the lateral rectus, eyeball, and superior rectus as per the method of Yokoyama et al ${ }^{2,3}$ (Figures 1 and 2). Horizontal MRI was performed to determine the orbital length between the center of the lens and the top of the muscle (Figure 3). A total of 20 high-myopia patients without double vision and 10 normal cases, who served as controls, were examined

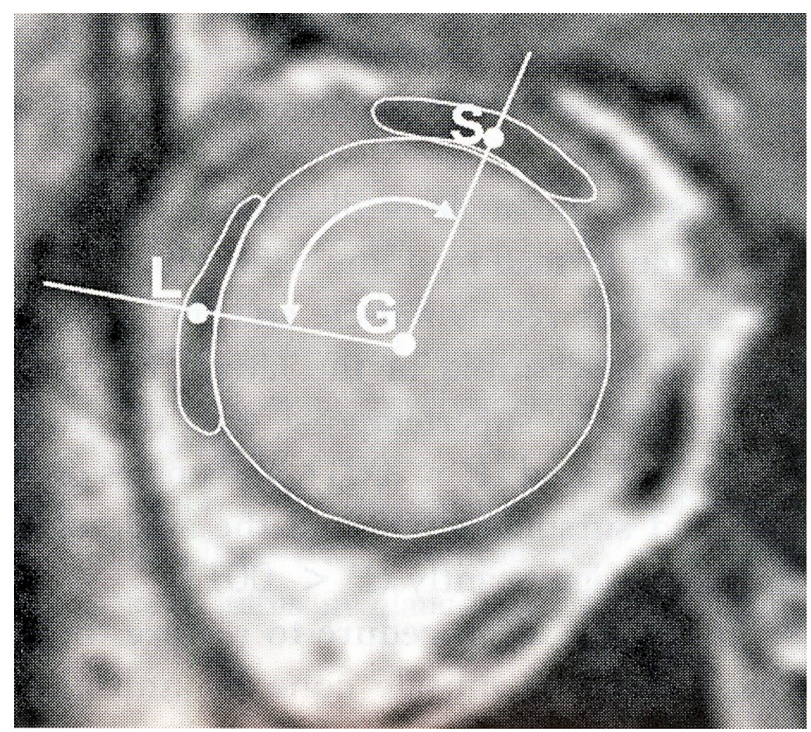

Figures I Lines were drawn between the eyeball and the extraocular muscles to measure the angle of the lateral rectus, eyeball, and superior rectus according to Yokoyama et al. ${ }^{2,3}$

Abbreviations: G, centroid of the glove; S, superior rectus; L, lateral rectus.

during the MRI study. Values are presented as mean \pm SD. Statistical significance of differences was determined using a 2-tailed $t$ test.

\section{Results \\ Case description of two typical cases Casel}

A 65-year-old woman visited our clinic for sudden-onset of double vision at far vision. Her corrected visual acuity was 20/30 OD (right eye) and 20/25 OS (left eye), and her

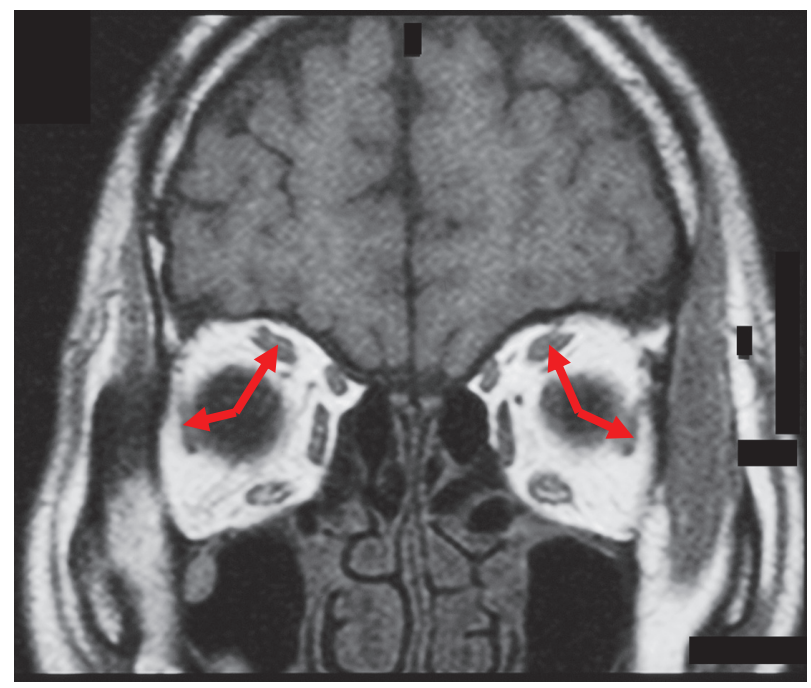

Figures 2 We drew lines between the eyeball and the extraocular muscles to measure the angle of the lateral rectus, eyeball, and superior rectus (Coronal MRI of case 2). 


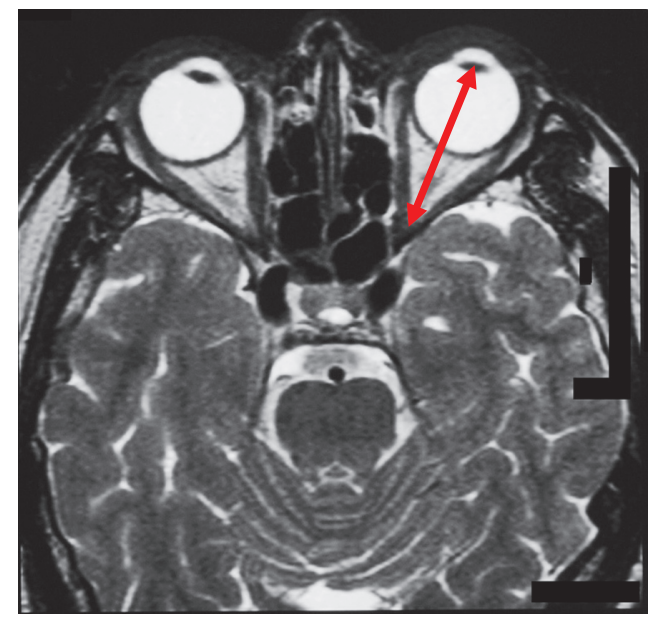

Figure 3 We measured the orbital length between the center of the lens and the top of the muscle cone using horizontal MRI.

refraction was $-7.0 \mathrm{D}$ OD and $-6.75 \mathrm{D}$ OS. Ophthalmological examination was almost completely normal except for slight bilateral cataract. Her axial length was $25.5 \mathrm{~mm}$ in her right eye and $25.5 \mathrm{~mm}$ in her left eye. She had an exophoria-tropia of 6 prism diopters (PD) at near vision and an esotropia of 6 PD at far vision. MRI indicated the presence of a long globe that filled the space of the orbits. A nasal shift of the superior rectus and an inferior shift of the lateral rectus were observed. But the medial rectus, inferior rectus, and superior oblique muscles did not shift. Both the lateral rectus and superior rectus were thin (Figure 4). The angle of her lateral rectus, eyeball, and superior rectus was 110 degrees in the right eye and 106 degrees in the left eye. Her orbital length was $43.2 \mathrm{~mm}$ in the right eye and $43.1 \mathrm{~mm}$ in the left eye.

\section{Case 2}

A 56-year-old man presented with diplopia at far vision for about 1 year. His corrected visual acuity was 20/20 OD and 20/20 OS, and his refraction was -13.75 D OD and $-13.25 \mathrm{D}$ OS. The anterior segments of both eyes were normal. The fundi showed slight chorio-retinal atrophy. His axial length was $29.0 \mathrm{~mm}$ in the right eye and $29.1 \mathrm{~mm}$ in the left eye. He had an esophoria of 6 PD at near vision and an esotropia of 16 PD for at far vision. Eso-deviation was seen in the Hess screen chart without limitation. MRI indicated a long globe filled the space of the orbits. A nasal shift of the superior rectus and an inferior shift of the lateral rectus were observed. But the medial rectus, inferior rectus, and superior oblique muscles did not shift. Both the lateral rectus and the superior rectus were thin (Figure 5).
A

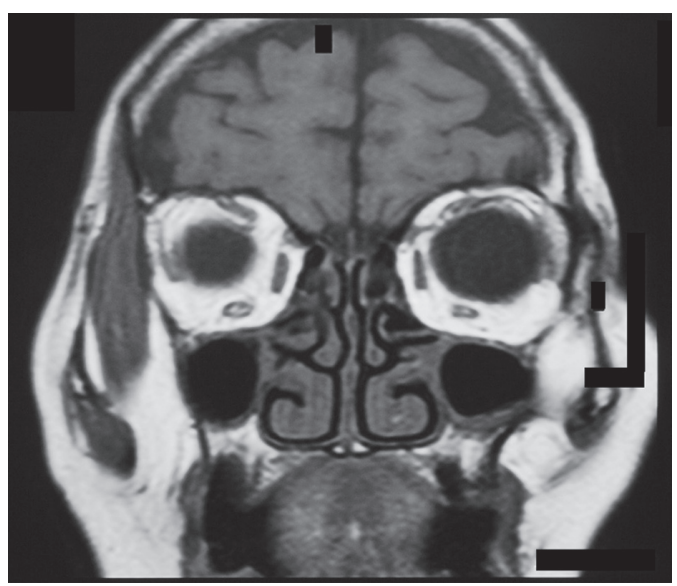

B

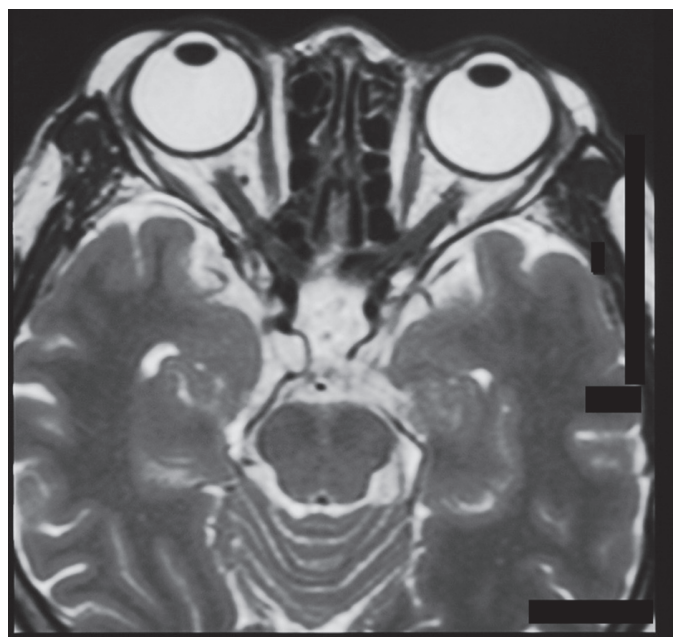

Figure 4 A) Case I: Nasal shift of the superior rectus and an inferior shift of the lateral rectus were observed. Both the lateral rectus and superior rectus were thin. B) Case I: A long globe fills the space of the orbits.

The angle of his lateral rectus, eyeball, and superior rectus was 122 degrees in the right eye and 140 degrees in the left eye. His orbital length was $43.9 \mathrm{~mm}$ in the right eye and $43.2 \mathrm{~mm}$ in the left eye.

\section{Clinical characteristics}

Age, sex, the presumed age at the onset of diplopia, refraction, eye position for the APCT, and the ocular axis length are listed in Table 1. Refraction ranged from -6.0 to -15.75 D. Ocular axis measurements ranged from 24.8 to 31.0 (mean \pm SD: $27.6 \pm 1.6$ ) $\mathrm{mm}$. Average ocular axis length was $27.6 \pm 1.3 \mathrm{~mm}$ in the high-myopia patients without double vision. These were significantly longer than that in the normal cases $(23.5 \pm 1.0 \mathrm{~mm})(P<0.05)$. For the 13 esophoria patients, there was 2 to $20 \mathrm{PD}$ at near fixation, and 8 to $30 \mathrm{PD}$ at far fixation. A total of 7 cases were exophoria-tropia at near vision, but all the cases were invariably esotropia at 
A

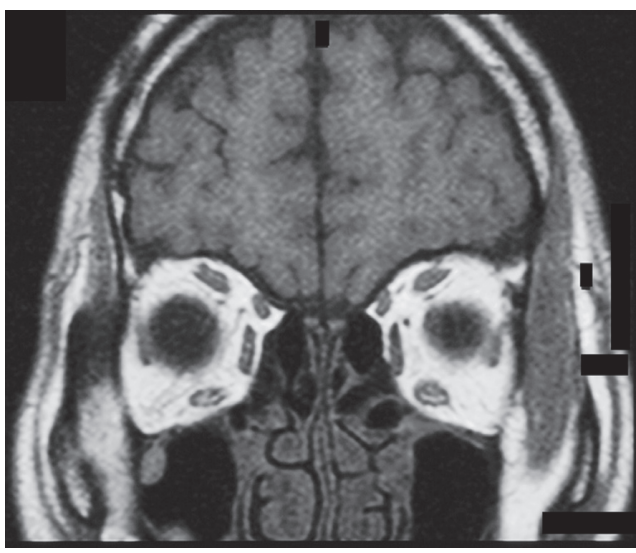

B

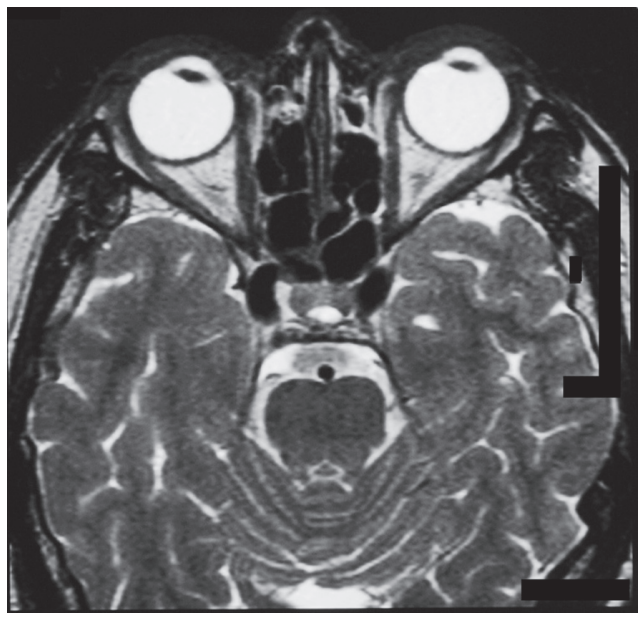

Figure 5 A) Case 2: Nasal shift of the superior rectus and an inferior shift of the lateral rectus were observed. B) Case 2: A long globe fills the space of the orbits.

far vision. The difference of the eye positions between the near and far vision ranged from 6 to $22 \mathrm{PD}$.

\section{MRI measurement}

MRI indicated there was elongation and enlargement of both eyes. This was especially prevalent in case 1 , where the long globe filled the orbital space and there was thinning of both the lateral and superior rectus (Figure 4 and $4 b$ ). In case 2, MRI demonstrated the presence of esodeviation (Figure 5b). In addition, we also noted a nasal shift of the superior rectus and an inferior shift of the lateral rectus (Figure 5a). The EOM angles in these patients ranged from 100 to $140(112.9 \pm 9.7)$ degrees, which was significantly higher $(P<0.05)$ than that seen in the high-myopia patients without double vision (average EOM angle, $99.2 \pm 2.8$ degrees) and normal cases (average EOM angle, $97.9 \pm 3.8$ degrees) (Tables 1 and 2). However, orbital lengths in the patients were 41.0 to $49.8(44.6 \pm 2.3) \mathrm{mm}$, which also significantly differed from the high-myopia patients without double vision (average orbital length, $49.9 \pm 2.0 \mathrm{~mm})(P<0.05)$, but did not significantly differ from normal cases $(45.5 \pm 1.6 \mathrm{~mm})$ $(P<0.05)$ (Tables 1 and 2$)$.

\section{Discussion}

In our clinic, divergence insufficiency associated with high myopia is not a rare phenomenon. We qualitatively have found a nasal shift of the superior rectus and an inferior shift of the lateral rectus in these cases. In the present quantitative study, using EOM angle, the shift was evident in all of our cases. However, the medial rectus, inferior rectus, and superior oblique muscles did not shift. In both the patients and the controls, the orbital lengths remained the same and at no time exhibited any change. Interestingly longer orbital lengths were noted in the high-myopia cases without double vision.

The one common feature that was found in our 20 patients but not in our controls and in those patients with high myopia without double vision was an EOM angle that was higher than 100 degrees. These results suggest that shifts of the EOM are highly associated with the divergence insufficiency. The presence of a long globe that fills the space of the orbits may be the factor responsible for the mechanical limitations that are more prominent in vergence. However, in the high-myopia cases without double vision, no mechanical limitations were noted, most likely due to the large orbital space that was found in these cases.

Yokoyama et al have reported that both the lateral rectus and superior rectus shifts were caused by an elongated posterior portion of the eyeball related to the high myopia. ${ }^{2,3}$ In a further study by Aoki et al, nasal shift of the superior rectus and an inferior shift of the lateral rectus were observed in acquired esotropia cases with high myopia. ${ }^{4}$ The high myopia with divergence insufficiency that was noted in our current cases is similar to these previous findings, although the degree seen was quite mild in our patients. An early study has suggested that an elongated eyeball causes neither EOM path shifts nor eyeball prolapse prior to the axial length attaining the critical level. ${ }^{5}$ Aydin et al used orbital CT to examine 2 cases of high myopia with abduction deficiency. Their results suggest that it is the large size of the long globe that fills the space of the orbits in conjunction with the tightness of the medial rectus that is responsible for the abduction limitations that are found in these cases. ${ }^{6}$ However, even though we excluded the abduction deficiency in our study, the esotropia mechanism seen during distance vision appears to be identical.

The lateral superior rectus (LR-SR) band joins the lateral and superior rectus muscle.

This LR-SR band originates from the lateral border of the superior rectus pulley and terminates in the superior border 
Table I High-myopia patients with divergence deficiency

\begin{tabular}{|c|c|c|c|c|c|c|c|c|c|}
\hline \multirow{2}{*}{$\frac{\text { Case }}{\text { Age/sex }}$} & \multirow{2}{*}{$\frac{\text { APCT }}{\text { Near/far }}$} & \multicolumn{2}{|c|}{ Refraction } & \multirow{2}{*}{$\frac{\text { Ocular }}{\mathbf{R}}$} & \multirow{2}{*}{$\begin{array}{l}\text { Axis } \\
L\end{array}$} & \multirow{2}{*}{$\begin{array}{l}\text { EOM } \\
\mathbf{R}\end{array}$} & \multirow{2}{*}{$\begin{array}{l}\text { Angle } \\
\mathrm{L}\end{array}$} & \multicolumn{2}{|c|}{ Orbital Length } \\
\hline & & $\mathbf{R}$ & $\mathbf{L}$ & & & & & $\mathbf{R}$ & $\mathbf{L}$ \\
\hline I) $65 / \mathrm{F}$ & XPT6/ET6 & -7.0 & -6.75 & 25.5 & 25.5 & 110 & 106 & 43.2 & 43.1 \\
\hline 2) $56 / \mathrm{M}$ & EP6/ETI6 & -13.75 & -13.25 & 29.0 & 29.1 & 122 & 140 & 43.9 & 43.2 \\
\hline 3) $65 / F$ & EP8/ET30 & -9.0 & -6.75 & 27.5 & 25.8 & 107 & 103 & 45.8 & 44.2 \\
\hline 4) $57 / \mathrm{F}$ & EP6/ETI8 & -9.5 & -8.75 & 27.2 & 26.8 & 114 & 114 & 48.2 & 49.8 \\
\hline 5) $74 / F$ & EP20/ET30 & -11.25 & -9.75 & 26.8 & 26.3 & 126 & 125 & 45.8 & 46.0 \\
\hline 6) $42 / \mathrm{F}$ & XP4/ET8 & -15.75 & -15.75 & 30.6 & 29.9 & 102 & 106 & 46.0 & 46.2 \\
\hline 7) $55 / \mathrm{M}$ & XPT8/ETIO & -7.5 & -6.0 & 26.6 & 25.8 & 115 & 108 & 44.2 & 44.1 \\
\hline 8) $50 / \mathrm{F}$ & XPT6/ET2 & -8.5 & -8.0 & 29.3 & 29.3 & 110 & 122 & 40.3 & 41.7 \\
\hline 9) $6 \mathrm{I} / \mathrm{F}$ & XP2/ET4 & -7.0 & -7.0 & 24.9 & 24.8 & 103.8 & 101.5 & 42.4 & 43.5 \\
\hline 10) $28 \mathrm{~F}$ & EPI8/ET25 & -11.0 & -12.5 & 27.6 & 27.6 & 105.5 & 107.2 & 46.2 & 45.8 \\
\hline II) $58 / F$ & EP8/ETI4 & -11.5 & -12.5 & 28.4 & 28.2 & 102 & 104 & 48.9 & 48.0 \\
\hline I2) $58 / \mathrm{F}$ & EP6/ET8 & -6.5 & -6.5 & 26.5 & 26.1 & 103 & 105 & 44.5 & 46.0 \\
\hline 13) $65 / \mathrm{M}$ & XP4/ET6 & -6.0 & -7.0 & 26.6 & 27.2 & 102 & 100 & 47.0 & 45.5 \\
\hline I4) $52 / F$ & EP4/ETI6 & -12.0 & -12.0 & 27.6 & 27.7 & 115 & 120 & 41.0 & 42.0 \\
\hline I5) 58/F & EP2/ETIO & -8.5 & -9.5 & 27.3 & 27.6 & 102 & 109 & 48.0 & 48.2 \\
\hline 16) $76 / \mathrm{M}$ & XP8/ET3 & -9.5 & -6.0 & 28.7 & 26.7 & 117 & 116.5 & 44.5 & 44.0 \\
\hline 17) $52 \mathrm{~F}$ & EP4/ETI6 & -12.0 & -12.0 & 27.6 & 27.6 & 115 & 120 & 41.0 & 42.0 \\
\hline 18) $49 \mathrm{~F}$ & EPI/ETI2 & -13.0 & -14.0 & 31.0 & 30.2 & 133 & 120 & 43.0 & 43.5 \\
\hline 19) $62 \mathrm{~F}$ & EP8/ETI8 & -6.5 & -7.0 & 25.9 & 26.0 & 114.2 & 118.8 & 43.8 & 42.5 \\
\hline 20) $53 \mathrm{~F}$ & EPI0/ET20 & -10.0 & -12.5 & 29.9 & 30.4 & $|2|$ & 130 & 46.0 & 46.5 \\
\hline
\end{tabular}

Abbreviations: $\mathrm{E}$, eso; $\mathrm{X}$, exo; P, phoria; T, tropia; APCT, alternating prism cover test; EOM, extraocular muscle.

of the lateral rectus pulley. In esotropia with high myopia, degeneration of the LR-SR band causes the lateral rectus muscle to slip inferiorly. ${ }^{7,8}$ Divergence deficiency associated with high myopia may be due to the degeneration or weakness of the LR-SR band.
Our results indicate that orbital MRI measurements can be used to evaluate high myopia with divergence insufficiency. Our findings also suggest that a mechanical cause related to axial high myopia should be considered in patients with non-neurological divergence insufficiency.

Table 2 High-myopia patients without double vision

\begin{tabular}{|c|c|c|c|c|c|c|c|c|}
\hline Case & Refra & & Ocular & Axis & EOM & Angle & Orbital & Length \\
\hline Age/sex & $\mathbf{R}$ & $\mathbf{L}$ & $\mathbf{R}$ & $\mathbf{L}$ & $\mathbf{R}$ & $\mathbf{L}$ & $\mathbf{R}$ & $\mathbf{L}$ \\
\hline I) $63 \mathrm{~F}$ & -9.0 & -8.5 & 27.2 & 27.0 & 96.4 & 97.4 & 52.2 & 50.8 \\
\hline 2) $40 \mathrm{M}$ & -10.5 & -9.5 & 28.1 & 27.6 & 99.0 & 97.1 & 51.8 & 50.2 \\
\hline 3) $33 \mathrm{M}$ & -11.0 & -11.0 & 28.2 & 28.1 & 102.8 & 102.2 & 48.4 & 48.2 \\
\hline 4) $66 \mathrm{~F}$ & -11.0 & -12.0 & 27.2 & 27.1 & 98.5 & 98.0 & 52.5 & 52.3 \\
\hline 5) $57 \mathrm{~F}$ & -9.0 & -9.0 & 25.8 & 26.0 & 98.0 & 96.0 & 49.0 & 49.0 \\
\hline 6) $75 F$ & -9.75 & -9.0 & 27.5 & 27.9 & 97.5 & 97.2 & 48.0 & 48.2 \\
\hline 7) $40 \mathrm{M}$ & -10.5 & -10.0 & 28.0 & 27.6 & 96.5 & 97.0 & 52.5 & 52.0 \\
\hline 8) $46 F$ & -11.0 & -7.5 & 25.5 & 25.5 & 99.0 & 95.7 & 52.0 & 52.0 \\
\hline 9) $35 \mathrm{~F}$ & -10.0 & -9.5 & 28.5 & 27.7 & 108.0 & 100.5 & 49.0 & 49.5 \\
\hline I0) $28 \mathrm{~F}$ & -8.0 & -8.0 & 25.1 & 25.2 & 102.1 & 98.2 & 46.5 & 46.5 \\
\hline I I) $55 \mathrm{~F}$ & -9.0 & -9.5 & 27.2 & 27.5 & 102.0 & 98.5 & 47.2 & 47.4 \\
\hline I2) $55 \mathrm{~F}$ & -6.25 & -6.25 & 25.8 & 25.9 & 95.2 & 98.2 & 53.0 & 53.2 \\
\hline I3) $40 \mathrm{~F}$ & -7.0 & -7.0 & 28.5 & 27.9 & 99.0 & 99.2 & 47.5 & 47.1 \\
\hline I4) $50 \mathrm{~F}$ & -13.5 & -14.5 & 29.5 & 30.3 & 102.5 & 103.4 & 52.0 & 50.5 \\
\hline I5) $38 \mathrm{M}$ & -14.0 & -13.0 & 29.6 & 29.2 & 100.3 & 98.2 & 50.6 & 50.0 \\
\hline 16) $50 \mathrm{M}$ & -13.5 & 14.0 & 29.4 & 29.0 & 98.4 & 98.7 & 52.1 & 52.3 \\
\hline I7) $56 \mathrm{~F}$ & -6.0 & -6.0 & 27.2 & 27.2 & 101.8 & 98.2 & 46.0 & 46.1 \\
\hline I8) $4 \mathrm{IF}$ & -13.0 & -13.5 & 27.5 & 27.5 & 107.2 & 103.7 & 48.0 & 48.0 \\
\hline 19) $49 \mathrm{M}$ & -11.0 & -9.0 & 28.0 & 27.0 & 100.5 & 100.3 & 51.5 & 52.0 \\
\hline 20) $68 \mathrm{~F}$ & -12.0 & -10.0 & 28.2 & 28.1 & 105.0 & 104.0 & 48.0 & 48.0 \\
\hline
\end{tabular}

Abbreviation: EOM, extraocular muscle. 
When diagnosing these types of patients, the presence of these conditions may be early initial signs that are indicative of fixed esotropia.

\section{Disclosure}

The authors report no conflicts of interest.

\section{References}

1. Kaynak S, Durak I, Canda T. Restrictive myopic myopathy: computed tomography, magnetic resonance imaging, echography, and histological findings. Br J Ophthalmol. 1994;78:414-415.

2. Yokoyama T, Tabuchi H, Ataka S, Shiraki K, Miki T, Mochizuki K. The mechanism of development in progressive esotropia with high myopia. In: de Faber JT, editor. Transactions of the 26th meeting. European Strabismological Association. Barcelona: Swets and Zeitlinger; 2000: 218-221.
3. Yamaguchi M, Yokoyama T, Shiraki K. Surgical procedure for correcting glove dislocation in highly myopic strabimus. Am J Ophthalmol. 2010; 149:341-346.

4. Aoki Y, Nishida Y, Hayashi O, et al. Magnetic resonance imaging measurements of extraocular muscle path shift and posterior eyeball prolapse from the muscle cone in acquired esotropia with high myopia. Am J Ophthalmol. 2003;136:482-489.

5. Krzizok TH, Kaufmann H, Traupe H. Elucidation of restrictive motility in high myopia by magnetic resonance imaging. Arch Ophthalmol. 1997; 115:1019-1027.

6. Aydin P, Kansu T, Sanac AS. High myopia causing bilateral abduction deficiency. J Clin Neuroophthalmol. 1992;12:163-165.

7. Oh SY, Clark RA, Velez F, Rosenbaum AL, Demer JL. Incomitant strabismus associated with instability of rectus pulleys. Invest Ophthalmol Vis Sci. 2002;43:2169-2177.

8. Rutar T, Demer JL. "Heavy eye" syndrome in the absence of high myopia: A connective tissue degeneration in elderly strabismic patients. JAAPOS. 2009;13:36-44.
Clinical Ophthalmology

\section{Publish your work in this journal}

Clinical Ophthalmology is an international, peer-reviewed journal covering all subspecialties within ophthalmology. Key topics include: Optometry; Visual science; Pharmacology and drug therapy in eye diseases; Basic Sciences; Primary and Secondary eye care; Patient Safety and Quality of Care Improvements. This journal is indexed on PubMed

Submit your manuscript here: http://www.dovepress.com/clinical-ophthalmology-journal

\section{Dovepress}

Central and CAS, and is the official journal of The Society of Clinical Ophthalmology (SCO). The manuscript management system is completely online and includes a very quick and fair peer-review system, which is all easy to use. Visit http://www.dovepress.com/testimonials. php to read real quotes from published authors. 